\title{
Strain Rate Imaging: Real World Scenario?
}

\section{Vivek Kumar $^{1 *}$, Ashish Jai Kishan ${ }^{2}$, Dr Lal C Daga ${ }^{2}$ and Sameer Shrivastava ${ }^{3}$}

${ }^{1}$ Principal Consultant, Fortis Escorts Heart Institute, New Delhi-110025, India

${ }^{2}$ Fellow Cardiology, Fortis Escorts Heart Institute, New Delhi-110025, India

${ }^{3}$ Director Cardiology, Fortis Escorts Heart Institute, New Delhi-110025, India

\begin{abstract}
The indices to measure the deformation of the myocardium by non-invasive techniques has proven to be a decisive modality. Done by strain and strain rate, both of these approaches allow comprehensive assessment of myocardial function and thereby broadening the spectrum of its clinical applications. They provide an early detection and quantification of myocardial dysfunction of different etiologies, assess the viability of the myocardium and finally the data provided by strain and strain rate are helpful for therapeutic decisions as well as useful for follow-up evaluations of post cardiac interventions. Their feasibility in measurement of the parameters however is marred by technical challenges, susceptible to artifacts as well as observer variability.

In this review the discussion elucidates the concepts of deformation imaging and also portrays comparatively two major deformation imaging methods (TDI-derived and speckle tracking 2D-strain derived). The focus shall be on the development of the technique and its limitations, together with current status of potential clinical applications. Despite the fact that further exploration is still awaited to bring an objectivity to the evaluation of the cardiovascular disease, presently considering of its applicability, these new tools of non-invasive cardiology have generated a great deal of interest amongst the cardiologist.
\end{abstract}

\section{Keywords: Strain; Strain rate imaging; Myocardium}

\section{Introduction}

In clinical cardiology, the quantification of regional myocardial function by means of non-invasive method is an important goal. The challenge which conventional echocardiography faces while analyzing the regional motion as well as assessing the regional myocardial function is that it is a visual estimation of wall motion which is very subjective and thus highly operator dependent. It has high interobserver and intraobserver variability. It also makes limited appraisal of the radial displacement and deformation, without assessing shortening and twisting of the myocardium [1,2]. For this very rationale, Doppler tissue imaging has been used to quantify ventricular function. It measures the velocity of myocardium (in the longitudinal direction from apical windows and in the radial direction from short-axis scans) during systole and diastole. Vis-a-vis the ejection fraction, Doppler is considered to be more sensitive as far as the subtle change of myocardial contractility is concerned [3]. Nevertheless, due to translational movement and tethering, tissue velocities are affected, thereby introducing an intricacy to discriminate a kinetic segment that are pulled (or tethered) from actively contracting segments [4]. Moreover, there is no uniform distribution of the velocities across the myocardium, as it decreases from base to apex, hence making it complicated to establish reference values.

With the introduction of the newer indices, myocardial strain and Strain Rate (SR), there has now been a potential to overcome these limitations. Both, strain that signifies the magnitude of the myocardial deformation and SRs which represents the rate of deformation, are an energy-requiring process that occurs in both systole and diastole. It permits a very comprehensive assessment of myocardial function as these indices have the ability to discriminate between both active as well as passive movement of myocardial segments, aids in quantification of intraventricular dys synchrony and assess components of myocardial function, including longitudinal myocardial shortening, thereby making the spectrum of its potential clinical applications very wide. We hereby review the applicability of strain and SR echocardiography in the real world patients.
The two important indices which would help in explaining the concept of strain and SR imaging are myocardial wall motion and wall deformation [5-9]. Wall motion is characterized by velocity and displacement; on the other hand, wall deformation is illustrated by strain and strain-rate. With the movement of an object in relation to time, it changes its position, gets displaced. If all the parts of this object moves with the same velocity, there occurs no deformation in the shape. However, instead if the movement of the various parts of the said object occurs with different velocities, it undergoes deformation and thus bringing change in its shape. Hence to differentiate between the active and passive myocardial segment movements, it is via the deformational analysis that has an upper hand compared to the wall motion measurements.

Strain is a measure of tissue deformation. With the ventricular contraction, two things happen. There is shortening of the muscle in the longitudinal and circumferential dimensions, known as a negative strain and there is thickening or lengthening in the radial direction, which is called as a positive strain.

Strain Rate (SR) is the rate by which the deformation occurs (deformation or strain per time unit). It is the primary parameter of deformation derived from tissue Doppler. The unit of strain rate is $\mathrm{s}^{-1}$. Indeed, SR seems to be a correlate of rate of change in pressure ( $\mathrm{dP} /$ $\mathrm{dt}$ ), a parameter that is used to reflect contractility, whereas strain is

*Corresponding author: Vivek Kumar, Principal Consultant, Fortis Escorts Heart Institute, New Delhi-110025, India, Tel: 98-187-97592; E-mail: visujata@hotmail.com

Received November 25, 2013; Accepted February 10, 2014; Published February 16,2014

Citation: Vivek Kumar, Kishan AJ, Daga LC, Shrivastava S (2014) Strain Rate Imaging: Real World Scenario? J Cardiovasc Dis Diagn 2: 145. doi:10.4172/2329 9517.1000145

Copyright: (c) 2014 Vivek Kumar, et al. This is an open-access article distributed under the terms of the Creative Commons Attribution License, which permits unrestricted use, distribution, and reproduction in any medium, provided the original author and source are credited. 
Citation: Vivek Kumar, Kishan AJ, Daga LC, Shrivastava S (2014) Strain Rate Imaging: Real World Scenario? J Cardiovasc Dis Diagn 2: 145. doi:10.4172/2329-9517.1000145

an analog of regional ejection fraction [10]. Strain is increased at all the levels of the wall stress with increase in the pre-load, while there is reduction of strain with the increase in the after-load. Although normal Left Ventricle (LV) cavity size has a limited impact on strain, small LV size is met with increase in radial strain and reduction in longitudinal strain. In contrast, SR is thought to be less related to pre-load and after-load. Heimdal et al. [6] measured the SR from comparison of adjacent tissue velocities and thus paving the way for the current era of myocardial strain measurement. Subsequently, strain has been measured using speckle tracking techniques [11,12]. Each of these methodologies presents its own clinical challenges.

\section{Tissue Doppler-Based Strain}

With the tissue Doppler techniques, velocity of movement of myocardium can be recorded and displayed as a parametric color image. Each pixel in this acquired image represents the velocity relative to the transducer. Graphically this data can also be expressed as the velocity of the myocardium relative to time (on the $\mathrm{x}$ axis). These recordings have revealed a descending gradation of velocity that exists from the LV base to apex, reflecting the contraction of the base toward a relatively fixed apex (Figure 1).

By measuring the motion of the myocardium with respect to the adjacent myocardium, one foregoes the limitation of the tethering effect which is encountered when the motion is compared with the transducer. A regression calculation is performed between the velocity data offered from the adjacent sites along the scan line which in turn provides an instantaneous gradient of velocity along a sample length. By combining these instantaneous data, an SR curve is procured (Figure 2) $[13,14]$. In two ways these measurements can be demonstrated, either as numerical curves or displayed in semi-quantitative color display.

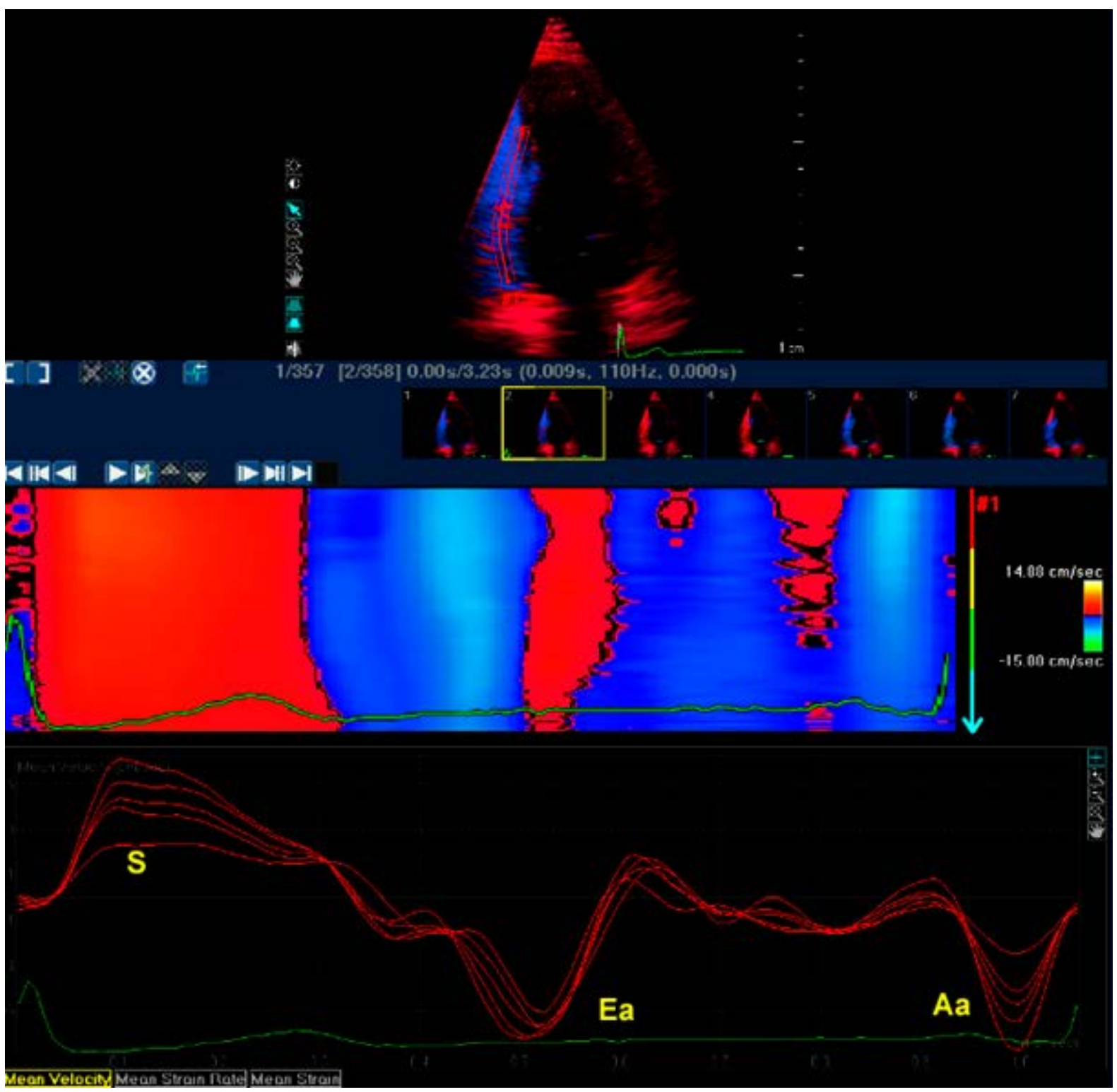

S: Systolic Velocity, Ea: Early Diastolic Vel., La: Late Diastolic Vel

Figure 1: Septal Tissue Doppler velocities showing gradual reduction from base to apex. 
Citation: Vivek Kumar, Kishan AJ, Daga LC, Shrivastava S (2014) Strain Rate Imaging: Real World Scenario? J Cardiovasc Dis Diagn 2: 145. doi:10.4172/2329-9517.1000145
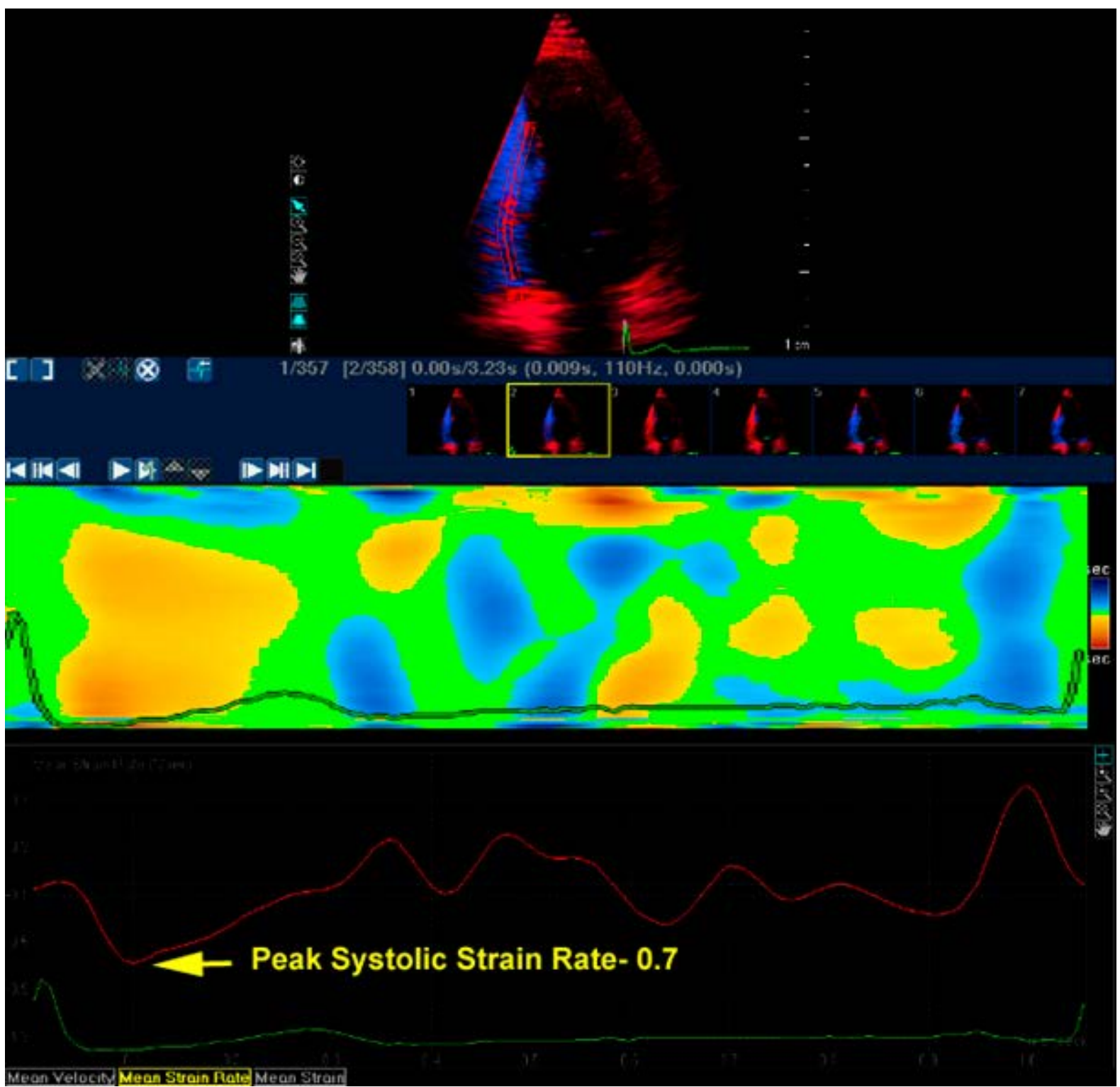

Figure 2: Normal average strain rate shown by numerical curve in lower panel, arrow showing peak systolic negative strain rate. Upper panel showing color-coded strain rate Yellow showing contraction during systole and in early diastole, cyan is for stretching during early and late diastole.

When displayed in color coded fashion, tri-color combination is used to illustrate deformation of the segments; green is no deformation, cyan for stretching and yellow for compression. Strain is thereby represented with the integration of this curve, which reveals instantaneous data on deformation that is shortening or lengthening (Figure 3). From the experimental as well as the clinical articles one thing that has come out with certainty is that by evaluating the movement of the tissue segment site of the myocardium with respect to the other site in a given sample volume reflects site specificity instead of using the tissue velocity data, where in the movement of the segment site is compared relative to transducer which is marred with tethering issues. This becomes more so highlighted when we are handling patients with coronary artery disease $[15,16]$.

\section{Limitations of Tissue Velocity}

First, signal noise poses a menace when there is comparison of adjacent velocities. In order to evade this reverberation artifact, one would need to optimize the velocity signal.

Second, by limiting the number of Doppler interrogating beams in an effort to maximize temporal resolution, spatial resolution gets compromised.

Third, alignment is another area of concern during the measurement of the strain. The error in measurement of the strain is documented especially in situation where in the axis of the contraction changes along the line of scan.

Fourth limitation would be where the concept of the dynamic motion of the myocardium per se is not taken into consideration. Myocardium has a unique wringing and torsional motion, which is not line with the unidirectional linear scan as the velocity regression tries to derive the data. Consequently, one has to face the fact that the sample inevitably shall no longer be within the scanning field. This inadequacy 
Citation: Vivek Kumar, Kishan AJ, Daga LC, Shrivastava S (2014) Strain Rate Imaging: Real World Scenario? J Cardiovasc Dis Diagn 2: 145. doi:10.4172/2329-9517.1000145

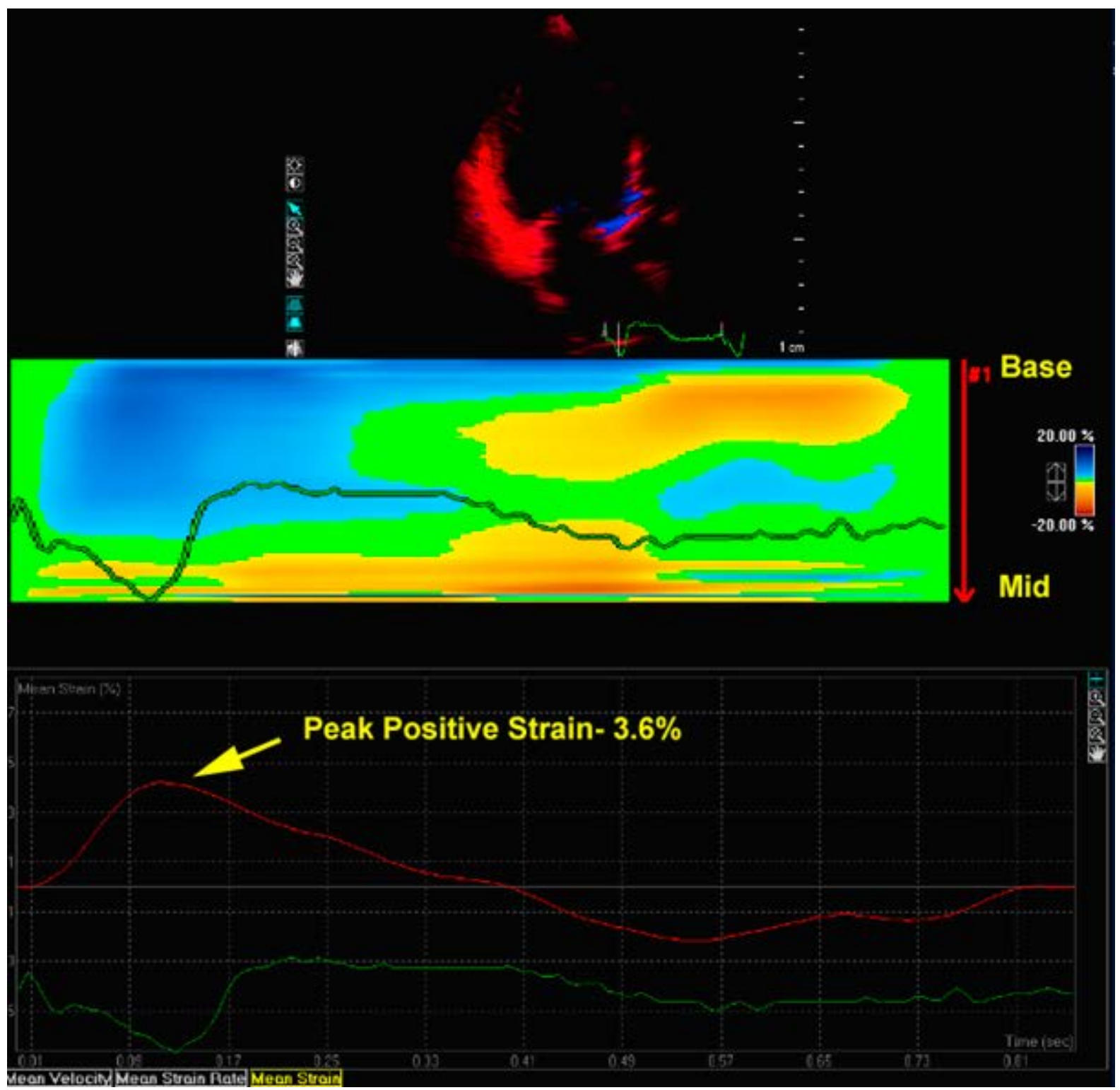

Figure 3: Strain image taken by selecting mid and basal segments of posterior wall showing systolic stretching without any contraction (peak positive strain=3.6\%) .

more so effects the diastolic measurements. Also in condition such as ischemic cardiomyopathy where the myocardial motion is not uniform it plays an important constrain.

Finally, the dynamic relationship shared between the cardiac cycle and the respiration system; there are changes in the angles which would waft the strain curve.

Despite these limitations tissue Doppler based strain evaluation has been extensively validated, initially with sonomicrometry [9] and subsequently have been confirmed by tagged magnetic resonance imaging, which is a gold standard [17].

\section{Two-Dimensional Speckle-Tracking (2D-STE)}

By using the frame-by-frame tracking of acoustic markers that are generated from interaction between the myocardium and the ultrasound waves, the 2D echocardiography-STE analyzes the myocardial motion $[13,18]$.
Two different tracking algorithms are used for the purpose of measurement. Both of these methods are independent of the insonation angle. By using these algorithms one can measure longitudinal, radial and circumferential strains. (Longitudinal-from apical views; radialfrom short-axis and apical views, and circumferential-from shortaxis views). 2D-STE can also help in assessing the more complex deformations, such as rotation, twist, and torsion [19] Compared to the Doppler, 2D has better intra as well as interobserver variability and are also when evaluated against noise, 2D fares better than Doppler [20]. To steer clear of the speckle decorrelation and to acquire a good image quality, frame rates of approximately 50 - 70 are needed for accurate tracking. Recent 3D wall motion tracking has been developed which got its validation in sheep using sono micrometry [21]. This new modality has the potential to be more accurately evaluate ventricular function in patients with ischemic heart disease.

2D strain has been validated against DSI [22] and strain measured 
using sono micrometry [23-25] and tagged MRI. [17,23,26,27] DSI and STE are compared in Table 1 and are compared with tagged MRI in Table 2.

\section{Clinical Implications}

In today's world strain rate imaging is considered to provide supplementary information to conventional $2 \mathrm{D}$ echocardiography in assessment of ventricular functions, regional wall motion abnormality, presence, extent and degree of hypokinesia. Both in children as well as adults, strain and strain rate imaging have been validated in being clinically feasible and also reproducible. At present maximum research is going on in the field of ischemic heart disease. Superiority of strain and strain rate imaging over tissue Doppler imaging for regional and global systolic function assessment is documented by previous studies. Recent advances in the management of end stage heart failure by left ventricular resynchronization has opened a new field for using strain rate imaging by transthorecic or intra-cardiac assessment of ventricular myocardial dyssynchrony (intramyocardial, intraventricular and interventricular). This method is found to be useful in other myocardial diseases, by providing additional information about heterogeneity of function, especially in various cardiomyopathies.

\section{Ventricular Function}

Systolic Function: Measurement of elastance is considered gold standard for the global assessment of LV function. Strain rate, which is an indirect measure of elastance, can be used as a noninvasive parameter for assessment regional myocardial function [28]. As compared to conventional $2 \mathrm{D}$ methods SRI is least dependent on preload and after load, does not influenced by manual boundary detection, and is considered superior over TDI in previous studies [29]. However, technical feasibility is still questioned in absence of a defined normal range, inter and intra-observer variability and need for an experienced operator.

\section{Diastolic function}

In absence of a direct measure of ventricular relaxation transmittal flow is used to assess diastolic functions, which is load-dependent. Tissue Doppler imaging is of incremental value in separating normal

\begin{tabular}{|c|c|}
\hline DSI & STE \\
\hline Doppler technique & 2D echo technique \\
\hline High temporal and spatial resolution & Good temporal and spatial resolution \\
\hline Measures natural strain & Measures Lagrangian strain \\
\hline Unaffected by translational motion & Affected by translational motion \\
\hline Highly insonation angle dependent & Independent of insonation angle \\
\hline Longitudinal and radial strain & Measures multiple deformations \\
\hline Requires high frame rates (100 to 130 ) & $\begin{array}{l}\text { Requires high quality image, more } \\
\text { modest frame rates }\end{array}$ \\
\hline Substantial interpretative variability & $\begin{array}{l}\text { Less sensitive to noise; better } \\
\text { interpretative variability }\end{array}$ \\
\hline
\end{tabular}

Table 1: Comparison of DSI and STE.

\begin{tabular}{|c|c|c|c|}
\hline $\begin{array}{c}\text { Temporal resolution } \\
\text { Availability }\end{array}$ & DSI & STE & Tagged MRI \\
\hline Acquisition time & Short & Good & Poor \\
\hline Postprocessing & Short & Short & Long \\
\hline 3 D imaging & No & Yes & Yes \\
\hline Expense & Inexpensive & Inexpensive & Expensive \\
\hline Availability & Widely available & Widely available & $\begin{array}{c}\text { Limited } \\
\text { availability }\end{array}$ \\
\hline
\end{tabular}

Table 2: Comparison of DSI, STE and Tagged MRI form pseudo normal LV filling pattern. Role of strain and strain rate imaging is still unclear in absence of studies.

\section{Right ventricular function}

Measurement of RV systolic function is of immense interest in the evaluation of patients after total correction for Fallot tetralogy, after Senning procedure for transposition, in ventricular non-compaction and in arrhythmogenic RV Cardiomyopathy [30,31]. Complex asymmetrical shape of right ventricle makes it prone to errors while assessing ventricular function by $2 \mathrm{D}$ echocardiography [32,33]. Tissue Doppler and strain rate imaging are emerging fields with encouraging results, however certain limitations like thinness of RV wall, complex contraction pattern of septum due to involvement of LV and RV both and difficulties in alignment of insonation angle are major hurdles to this technique.

\section{Ischemic Heart Disease}

Great concern lies in evaluating patients of ischemic heart disease ranging from differentiation of acute from chronic ischemia, transmural from subendocardial infarction, to detection of viability and small region of myocardial insult. Each of these issues helps in deciding management strategies and prognostication.

Differentiation of viable form nonviable myocardium has major clinical implications in terms of management decisions, however conventional methods like $\mathrm{Q}$ waves in electrocardiogram and myocardial wall thinning are not reliable markers for detection of extent of necrosis $[34,35]$. Stress echocardiography is an efficient tool for detection of reversible myocardial ischemia. An improvement in reproducibility and less inter observer variability has been seen with incorporation of tissue velocity to stress echocardiography [15].Strain rate imaging is also integrated to the stress echocardiography with the notion that it has the ability to discriminate between active contractions vs. passive movement, less amenable to myocardial tethering and is capable in detection of slight changes in wall motion with promising results $[15,29,34]$. Although the most sensitive marker for ischemia is yet to be established, measurements like loss of homogenous distribution of strain parameters, reduction and even reversal of early systolic regional strain rates, delayed time of onset of relaxation, and increase in postsystolic thickening appears appropriate for the detection of inducible ischemia [36]. Technical feasibility of SR imaging with do butamine stress echocardiography has been proved in various studies [36,37]. There is a proportionate increase in systolic strain rate with increasing dose of dobutamine and a blunted response is considered significant for detection of significant stenosis. The proposed cutoffs values for detection of ischemia are an optimal longitudinal SR of $0.8 / \mathrm{s}$ (sensitivity $75 \%$, specificity $63 \%$ ) and a peak systolic strain of $10 \%$ (sensitivity $86 \%$, specificity $83 \%$ ) [38]. A post systolic shortening cutoff of $35 \%$ gave a sensitivity of $82 \%$ and specificity of $85 \%$ for the detection of ischemia [39]. Dobutamine causes reduction in time to onset of relaxation in normal myocardium, while in ischemic segments this onset is delayed. A change in TR of $>20 \%$ was proposed as a cutoff for identification of new wall motion abnormalities with a sensitivity of $95 \%$ and a specificity of $75 \%$ [40]. Subendocardial early diastolic SR during lowdose dobutamine infusion was found to be more sensitive parameter of ischemia in one of the studies [41]. SRI is found to be superior to TDI as a noninvasive tool for this differentiation while considering MRI and PET as gold standards, and has direct relationship to infarct size [42]. Infarcted myocardium was characterized by significantly reduced systolic and diastolic deformation rates [42]. Post-systolic shortening is another important parameter for detection of viable tissue after acute myocardial infarction $[37,38,42,43]$. 
Citation: Vivek Kumar, Kishan AJ, Daga LC, Shrivastava S (2014) Strain Rate Imaging: Real World Scenario? J Cardiovasc Dis Diagn 2: 145. doi:10.4172/2329-9517.1000145

In patients of acute coronary syndrome, presence of post-systolic shortening along with reduced systolic SR, during ejection correctly identified acutely ischemic myocardium [44]. High, abnormal SR can easily recognize post-systolic shortening during the isovolumic relaxation period [44]. This phenomenon was observed in the ischemic myocardium and along the viable border zone in initial period of insult. The extent of myocardium that exhibits post-systolic shortening approximates the extent of myocardium at ischemic risk [45]. Systolic myocardial velocity gradient are recovered partially while post systolic shortening often disappears after reperfusion in myocardial walls with non-transmural infarction, but not with transmural infarction [46]. Partial recovery of systolic myocardial velocity gradient identifies stunned myocardium and can be identified by blunted systolic SR and strain that eventually increased during a dobutamine challenge.

\section{Cardiomyopathy}

Till recent times, detection of ventricular asynchrony had been based on visual detection of asynchronous myocardial motion which was visually estimated by 2D images, Septal Posterior Wall Delay (SPWD) on M-mode and prolongation of pre-ejection period on Doppler imaging. Except for SPWD, all other methods are not sensitive enough to detect a regional delay of $>70 \mathrm{~ms}$; moreover SPWD is limited to two segments only.

With increasing number of non-responders the apparent need for improved patient selection and follow-up has led to the further advancement in technology with incorporation of TDI and SRI with high temporal resolution to overcome these limitations. The pulsedwave technique has higher temporal resolution but time-consuming measurement of Ts, discrepancy in ideal site for sampling and higher inter and intra observer variability has limited its application (Figure 4A) [47]. Colour Coded Tissue Velocity (CTDI) and deformation imaging (SRI) with incorporation of parametric imaging are used extensively for dyssynchrony assessment because of its lesser dependence on operator, less complex interpretation and direct comparisons of several segments in the same cardiac cycle (Figure 4B). However, reproducibility and reliability of this new parametric imaging technique still has to be

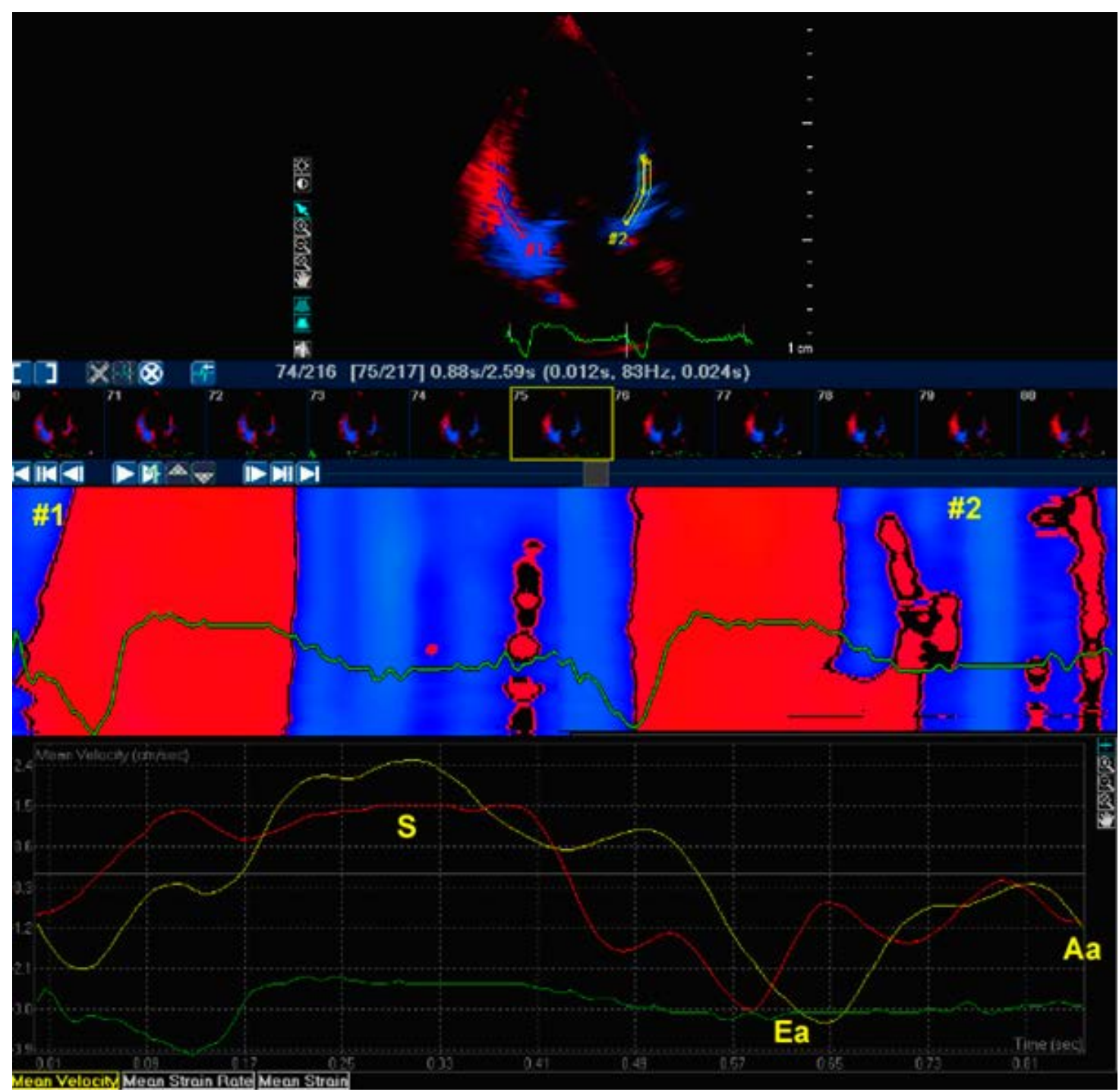

Figure 4A: Simultaneous mean TDI velocity from mid-basal inferior wall (Red) and mid basal anterior wall (Blue). No definite systolic peak in inferior wall tissue velocities. 
Citation: Vivek Kumar, Kishan AJ, Daga LC, Shrivastava S (2014) Strain Rate Imaging: Real World Scenario? J Cardiovasc Dis Diagn 2: 145. doi:10.4172/2329-9517.1000145

evaluated. The presence of regional dyssynchrony (differential onset of contraction) can be identified using strain rate imaging with enhanced reproducibility. Post systolic contraction is also found to be an efficient marker of recruitable contractile reserve especially in non-ischemic Cardiomyopathy patients. As this is also a marker of ischemia and might not be modified by changing activation sequence using bi-ventricular pacing, absence of ischemia should be documented [48]. In recent studies regional strain patterns between two consecutive segments were compared in off pacing with documentation of significant dyssynchrony and its improvement with active bi-ventricular pacing with optimisation of AV and VV delay [49]. The quantitative analysis of the regional deformation properties showed that there is marked discrepancy between onset of motion vs. onset of deformation which is significantly delayed; this also proves superiority of deformation imaging.

Recent studies using SR imaging has given better insight in understanding the beneficial effects of biventricular pacing [50,51]. The proposed explanation is that by reducing the abnormal stretch and redistribution of regional systolic strain there is unloading of the dyssynchronus segments which may normalize the abnormal myocardial calcium handling and may reduce arrhythmogenecity [52].

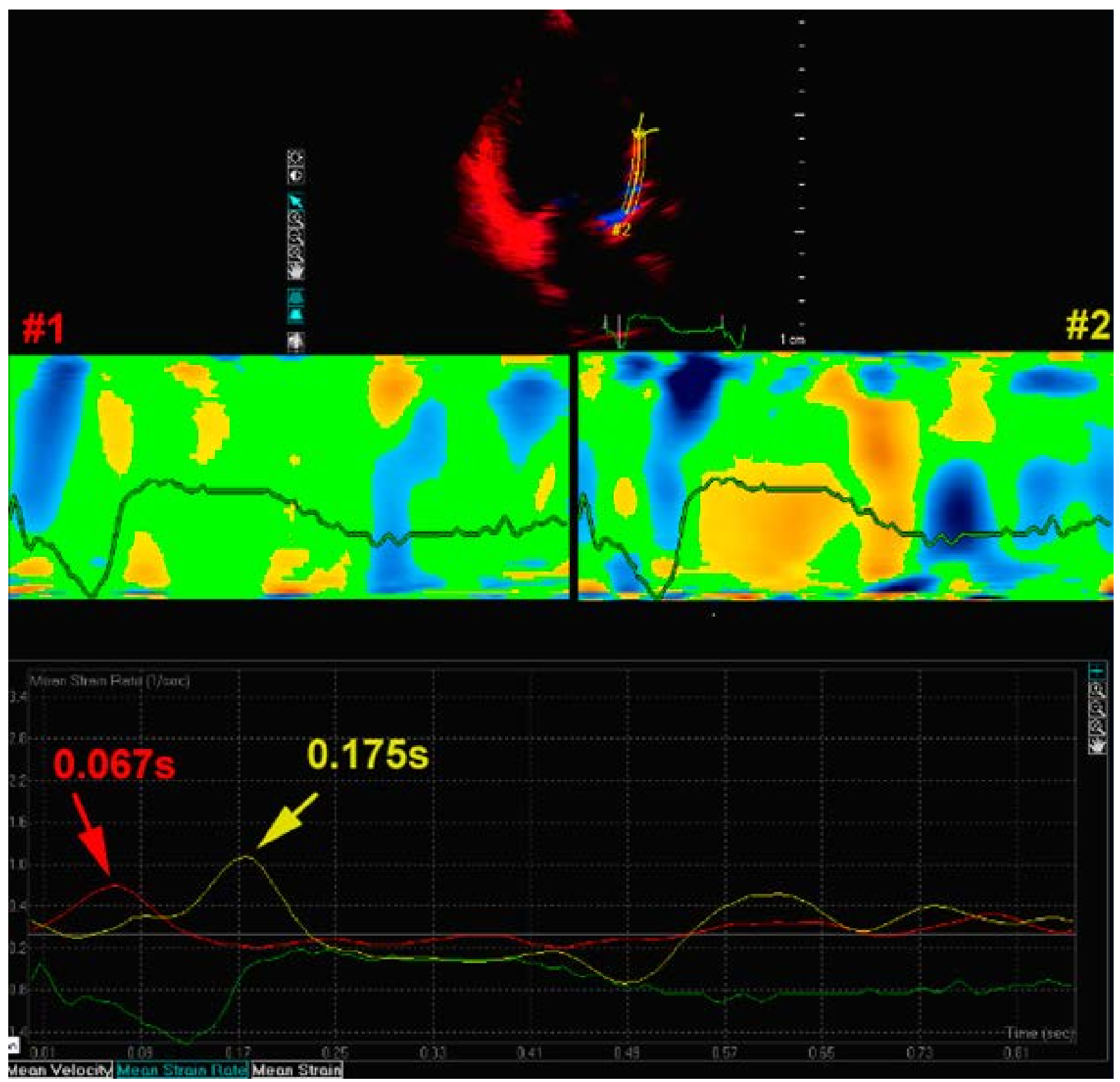

Figure 4B: Simultaneous mean strain rate from mid-basal inferior wall (Red) and mid basal anterior wall (Yellow). Intra ventriculardys synchrony reported between two walls with a time delay of $108 \mathrm{~ms}$. Upper panel shows akinesia in inferior wall depicted in green color during systole in left panel. Right panel shows systolic contraction in mid segments of anterior wall. 
Role of strain and strain rate imaging in evaluation of sub-clinical myocardial involvement and its response to treatment in non-cardiac diseases such as amyloidosis, diabetic heart disease, Friedrich ataxia and Fabry disease is also an evolving field with promising results [5355].

\section{Synopsis}

Regardless of various researches and subsequent data that have considerably validated its clinical utility, DSI has still not become a routine standard modality of practice in the real world. The reason of its failure to catch up is because it requires expertise, highly trained operators, acquisition of the data is time-consuming and processing is met with high interobserver variability. In addition of being $1 \mathrm{D}$, its highly angle-dependent nature and limited spatial resolution with reduced signal-to-noise ratio are important limitations. In contrast, STE is more likely to become standard practice because it may be semi-automated, therefore less time consuming, has increased reproducibility, greater signal to noise, no angle dependency, and is multidirectional. Finally, although temporal and magnitude markers of regional strain and changes in the strain curve (e.g., postsystolic shortening) will find importance in specific situations, global longitudinal strain, which correlates with LV ejection fraction and predicts functional recovery and cardiovascular morbidity and mortality, has the potential to become a routine clinical measurement in the evaluation of CAD. Future applications of this technique might be in 1/- detection of cardiotoxicity in cancer patients undergoing chemotherapy, 2/- predicting rejection of transplanted heart in cardiac transplantation, and in 3/- effect of intracoronary stem cell therapy on left ventricular function in acute myocardial infarction.

\section{Conclusion}

With the entry into the twenty first century, the field of non-invasive cardiology has met with enlivening advances with both Dopplerderived and 2D Echocardiographic-derived myocardial strain imaging. Strain and SR have shown to be sensitive in detection of early disease; they correlate well with other measures of cardiac function, and also detect changes in myocardial contractility, both normal and abnormal, across a wide range of ischemic syndromes. These newer modalities have paved a fresh path to analyze the complex deformations of the left ventricle. They also give an impression to enhance detection of both coronary artery disease and viable myocardium, predict the sequelae of myocardial infarction, the response to reperfusion, and prognosis. Presently it is expected that with further technological refinements, echocardiographic strain imaging would provide much needed objectivity to the evaluation of cardiovascular disease, especially in the patients with coronary artery disease. Calculation of strain and strain rate in 3 dimensions during the same cardiac cycle is probably going to be the new development in deformation imaging by echocardiography.

\section{References}

1. Sheehan FH (2002) Quantitative evaluation of regional left ventricular systolic function. In: Otto CM (Edns)The Practice of Clinical Echocardiography. Philadelphia: WB Saunders Company, 65-87.

2. Perk G, Tunick PA, Kronzon I (2007) Non-Doppler two-dimensional strain imaging by echocardiography--from technical considerations to clinical applications. J Am Soc Echocardiogr 20: 234-243.

3. Nesbitt GC, Mankad S, Oh JK (2009) Strain imaging in echocardiography: methods and clinical applications. Int J Cardiovasc Imaging 25 Suppl 1: 9-22.

4. Pislaru C, Abraham TP, Belohlavek M (2002) Strain and strain rate echocardiography. CurrOpinCardiol 17: 443-454.

5. Sutherland GR, Stewart MJ, Groundstroem KW, Moran CM, Fleming A, et al.
(1994) Color Doppler myocardial imaging: a new technique for the assessment of myocardial function. J Am Soc Echocardiogr 7: 441-458.

6. Heimdal A, Støylen A, Torp H, Skjaerpe T (1998) Real-time strain rate imaging of the left ventricle by ultrasound. J Am Soc Echocardiogr 11: 1013-1019.

7. Stoylen A, Heimdal A, Bjornstad K, Torp HG, Skjaerpe T (1999) Strain Rate Imaging by Ultrasound in the Diagnosis of Regional Dysfunction of the Left Ventricle. Echocardiography 16: 321-329.

8. Veyrat C, Pellerin D, Larrazet F (1997) [Myocardial Doppler tissue imaging past, present and future]. Arch Mal Coeur Vaiss 90: 1391-1402.

9. Urheim S, Edvardsen T, Torp H, Angelsen B, Smiseth OA (2000) Myocardia strain by Doppler echocardiography. Validation of a new method to quantify regional myocardial function. Circulation 102: 1158-1164.

10. Weidemann F, Jamal F, Sutherland GR, Claus P, Kowalski M, et al. (2002) Myocardial function defined by strain rate and strain during alterations in inotropic states and heart rate. Am J Physiol Heart Circ Physiol 283: H792-799.

11. D'hooge J, Konofagou E, Jamal F, Heimdal A, Barrios L, et al. (2002) Twodimensional ultrasonic strain rate measurement of the human heart in vivo. IEEE Trans Ultrason Ferroelectr Freq Control 49: 281-286.

12. Reisner SA, Lysyansky P, Agmon Y, Mutlak D, Lessick J, et al. (2004) Global longitudinal strain: a novel index of left ventricular systolic function. J Am Soc Echocardiogr 17: 630-633.

13. D'hooge J, Heimdal A, Jamal F, Kukulski T, Bijnens B, et al. (2000) Regiona strain and strain rate measurements by cardiac ultrasound: principles, implementation and limitations. Eur J Echocardiogr 1: 154-170.

14. Sutherland GR, Di Salvo G, Claus P, D’hooge J, Bijnens B (2004) Strain and strain rate imaging: a new clinical approach to quantifying regional myocardial function. J Am Soc Echocardiogr 17: 788-802.

15. Armstrong G, Pasquet A, Fukamachi K, Cardon L, Olstad B, et al. (2000) Use of peak systolic strain as an index of regional left ventricular function: comparison with tissue Doppler velocity during dobutamine stress and myocardial ischemia. J Am Soc Echocardiogr 13:731-737.

16. Abraham TP, Nishimura RA, Holmes DR Jr, Belohlavek M, Seward JB (2002) Strain rate imaging for assessment of regional myocardial function: results from a clinical model of septal ablation. Circulation 105: 1403-1406.

17. Edvardsen T, Gerber BL, Garot J, Bluemke DA, Lima JA, et al. (2002) Quantitative assessment of intrinsic regional myocardial deformation by Doppler strain rate echocardiography in humans: validation against threedimensional tagged magnetic resonance imaging. Circulation 106: 50-56.

18. Leitman M, Lysyansky P, Sidenko S, Shir V, Peleg E, et al. (2004) Twodimensional strain-a novel software for real-time quantitative echocardiographic assessment of myocardial function. J Am Soc Echocardiogr 17: 1021-1029.

19. Geyer H, Caracciolo G, Abe H, Wilansky S, Carerj S, et al. (2010) Assessment of myocardial mechanics using speckle tracking echocardiography: fundamentals and clinical applications. J Am Soc Echocardiogr 23: 351-369.

20. Oxborough D, Batterham AM, Shave R, Artis N, Birch KM, et al. (2009) Interpretation of two-dimensional and tissue Doppler-derived strain (epsilon) and strain rate data: is there a need to normalize for individual variability in left ventricular morphology? Eur J Echocardiogr10: 67- 682.

21. Seo $Y$, Ishizu T, Enomoto $Y$, Sugimori H, Yamamoto M, et al. (2009) Validation of 3 -dimensional speckle tracking imaging to quantify regional myocardial deformation. CircCardiovasc Imaging 2: 451-459.

22. Modesto KM, Cauduro S, Dispenzieri A, Khandheria B, Belohlavek M, et al. (2006) Two-dimensional acoustic pattern derived strain parameters closely correlate with one-dimensional tissue Doppler derived strain measurements. Eur J Echocardiogr7: 315-321.

23. Amundsen $\mathrm{BH}$, Helle-Valle $\mathrm{T}$, Edvardsen $\mathrm{T}$, Torp $\mathrm{H}$, Crosby $\mathrm{J}$, et al. (2006) Noninvasive myocardial strain measurement by speckle tracking echocardiography: validation against sonomicrometry and tagged magnetic resonance imaging. J Am Coll Cardiol47:789 -793.

24. Korinek J, Wang J, Sengupta PP, Miyazaki C, Kjaergaard J, et al. (2005) Twodimensional strain--a Doppler-independent ultrasound method for quantitation of regional deformation: validation in vitro and in vivo. J Am Soc Echocardiogr 18: $1247-1253$.

25. Reant $P$, Labrousse L, Lafitte S, Bordachar P, Pillois X, et al. (2008) Experimental validation of circumferential, longitudinal, and radial 2-dimensional strain during 
dobutamine stress echocardiography in ischemic conditions. J Am Coll Cardiol 51:149-157.

26. Roes SD, Mollema SA, Lamb HJ, van derWall EE, de Roos A, et al. (2009) Validation of echocardiographic two-dimensional speckle tracking longitudinal strain imaging for viability assessment in patients with chronic ischemic left ventricular dysfunction and comparison with contrast enhanced magnetic resonance imaging. Am J Cardiol 104: 312-317.

27. Cho GY, Chan J, Leano R, Strudwick M, Marwick TH (2006) Comparison of two-dimensional speckle and tissue velocity based strain and validation with harmonic phase magnetic resonance imaging. Am J Cardiol 97: 1661-1666.

28. Weidemann F, Eyskens B, Mertens L, Dommke C, Kowalski M, et al. (2002) Quantification of regional right and left ventricular function by ultrasonic strain rate and strain indexes after surgical repair of tetralogy of Fallot. Am J Cardio 90: 133-138.

29. Eyskens B, Weidemann F, Kowalski M, Bogaert J, Dymarkowski S, et al (2004) Regional right and left ventricular function after the Senning operation: an ultrasonic study of strain rate and strain. Cardiol Young 14: 255-264.

30. Aebischer NM, Czegledy F (1989) Determination of right ventricular volume by two-dimensional echocardiography with a crescentic model. J Am SocEchocardiogr 2: 110-118

31. Levine RA, Gibson TC, Aretz T, Gillam LD, Guyer DE, et al. (1984) Echocardiographic measurement of right ventricular volume. Circulation 69: 497-505.

32. Phibbs B (1983) "Transmural" versus "subendocardial" myocardial infarction an electrocardiographic myth. J Am CollCardiol 1: 561-564.

33. Moon JC, De Arenaza DP, Elkington AG, Taneja AK, John AS, et al. (2004) The pathologic basis of $\mathrm{Q}$-wave and non-Q-wave myocardial infarction: a cardiovascular magnetic resonance study. J Am CollCardiol 44: 554-560.

34. Fathi R, Cain P, Nakatani S, Yu HC, Marwick TH (2001) Effect of tissue Doppler on the accuracy of novice and expert interpreters of dobutamine echocardiography. Am J Cardiol 88: 400-405.

35. Tsutsui H, Uematsu M, Shimizu H, Yamagishi M, Tanaka N, et al. (1998) Comparative usefulness of myocardial velocity gradient in detecting ischemic myocardium by a dobutamine challenge. J Am CollCardiol 31: 89-93.

36. Kukulski T, Jamal F, Herbots L, D'hooge J, Bijnens B et al. (2003) Identification of acutely ischemic myocardium using ultrasonic strain measurements. A clinical study in patients undergoing coronary angioplasty. J Am CollCardiol 41: 810-819.

37. Weidemann F, Dommke C, Bijnens B, Claus P, D'hooge J, et al. (2003) Defining the transmurality of a chronic myocardial infarction by ultrasonic strain-rate imaging: implications for identifying intramural viability: an experimental study. Circulation 107: 883-888.

38. Abraham TP, Belohlavek M, Seward JB, Pellikka, Patricia A (2001) Abnorma regional contractionrelaxation patterns during dobutamine infusion predict angiographic coronary artery disease. Circulation 2001, 104(Suppl S):S-2965.

39. Jamal F, Strotmann J, Weidemann F, Kukulski T, D'hooge J, et al. (2001) Noninvasive quantification of the contractile reserve of stunned myocardium by ultrasonic strain rate and strain. Circulation 104: 1059-1065.

40. Tsutsui H, Uematsu M, Yamagishi M, Haruta S, Shimakura T, et al. (2000) Usefulness of the subendocardial myocardial velocity gradient in low-dose dobutamine stress echocardiography. Heart Vessels 15: 11-17.

41. Hoffmann R, Altiok E, Nowak B, Heussen N, Kühl H, et al. (2002) Strain rate measurement by doppler echocardiography allows improved assessment of myocardial viability inpatients with depressed left ventricular function. J Am CollCardiol 39: 443-449.

42. Pislaru C, Belohlavek M, James B Seward, Greenleaf JF, Marek Belohlavek (2001) Higher strain rate during isovolumic relaxation higher than during ejection phase characterizes ischemic myocardium. J Am CollCardiol 37(Suppl A): 401A.
43. Pislaru C, Belohlavek M, Bae RY, Abraham TP, Greenleaf JF, et al. (2001) Regional asynchrony during acute myocardial ischemia quantified by ultrasound strain rate imaging. J Am CollCardiol 37: 1141-1148.

44. Derumeaux G, Loufoua J, Gérard Pontier, Alain Cribier, Michel Ovize (2001) Tissue Doppler imaging differentiates transmural from nontransmural acute myocardial infarction after reperfusion therapy. Circulation 103: 589-596.

45. Anagnostopoulos PC, Belohlavek M, Dzeja P, James B Seward, Rocheste (2001) Strain-rate echocardiography: a new quantitative tool for measurement of regional myocardial function during experimentally altered myocardial energetics. J Am CollCardiol 37(Suppl A): 443A.

46. Piet Claus, Bart Bijnens, Ole-Alexander Breithardt, George R, Sutherland OA (2003) Why ischemic hearts respond less to cardiac resynchronisation therapy. A modeling study. In: Magnin IE, Montagnat J, Clarysse $P$, et al., editors. Functional imaging and modeling of the heart - Proceedings of the second international workshop on functional imaging and modeling of the heart. Berlin: Springer p. 287-294

47. Breithardt OA, Stellbrink C, Herbots L, Claus P, Sinha AM, et al. (2003) Cardiac resynchronization therapy can reverse abnormal myocardial strain distribution in patients with heart failure and left bundle branch block. J Am CollCardiol 42 486-494.

48. Prinzen FW, Augustijn CH, Arts T, Allessie MA Reneman RS (1990) Redistribution of myocardial fiber strain and blood flow by asynchronous activation. Am J Physiol 259: H300-308.

49. Prinzen FW, Hunter WC, Wyman BT, McVeigh ER (1999) Mapping of regional myocardial strain and work during ventricular pacing: experimental study using magnetic resonance imaging tagging. J Am Coll Cardiol 33: 1735-1742.

50. Hasenfuss G, Pieske B (2002) Calcium cycling in congestive heart failure. J Mol Cell Cardiol 34: 951-969.

51. Wang Z, Taylor LK, Denney WD, Hansen DE (1994) Initiation of ventricula extrasystoles by myocardial stretch in chronically dilated and failing canine left ventricle. Circulation 90: 2022-2031.

52. Kato TS, Noda A, Izawa H, Yamada A, Obata K, et al. (2004) Discrimination of nonobstructive hypertrophic cardiomyopathy from hypertensive left ventricular hypertrophy on the basis of strain rate imaging by tissue Doppler ultrasonography. Circulation 110: 3808-3814.

53. Andersen NH, Poulsen SH, Eiskjaer H, Poulsen PL, Mogensen CE (2003) Decreased left ventricular longitudinal contraction in normotensive and normoalbuminuric patients with type II diabetes mellitus: a Doppler tissue tracking and strain rate echocardiography study. Clin Sci (Lond) 105: 59-66.

54. Weidemann F, Eyskens B, Mertens L, Di Salvo G, Strotmann J, et al. (2003) Quantification of regional right and left ventricular function by ultrasonic strain rate and strain indexes in Friedreich's ataxia. Am J Cardiol 91: 622-626.

55. Weidemann F, Breunig F, Beer M, Sandstede J, Turschner O, et al. (2003) Improvement of cardiac function during enzyme replacement therapy in patients with Fabry disease: a prospective strain rate imaging study. Circulation 108: 1299-1301. 